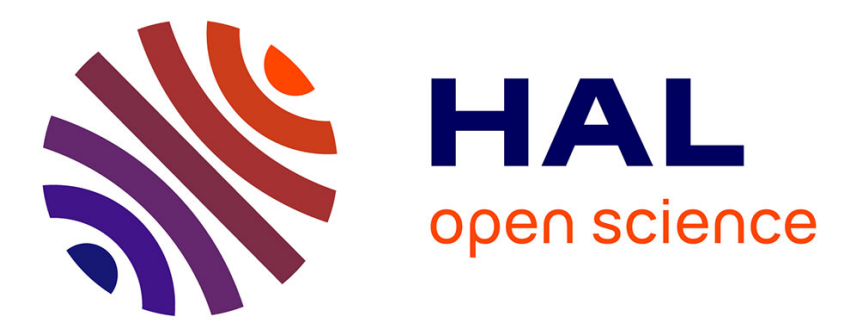

\title{
PVD Coated Mill Rolls for Cold Rolling of Stainless Steel Strips: Tribological and Mechanical Laboratory Tests
}

Choumad Ould, Xavier Badiche, Pierre Montmitonnet, Yves Gachon

\section{- To cite this version:}

Choumad Ould, Xavier Badiche, Pierre Montmitonnet, Yves Gachon. PVD Coated Mill Rolls for Cold Rolling of Stainless Steel Strips: Tribological and Mechanical Laboratory Tests. 40th NAMRC North American Manufacturing Research Conference, Jun 2012, Notre-Dame, Indiana, United States. pp.234-243. hal-00724779

HAL Id: hal-00724779

https://hal-mines-paristech.archives-ouvertes.fr/hal-00724779

Submitted on 23 Aug 2012

HAL is a multi-disciplinary open access archive for the deposit and dissemination of scientific research documents, whether they are published or not. The documents may come from teaching and research institutions in France or abroad, or from public or private research centers.
L'archive ouverte pluridisciplinaire HAL, est destinée au dépôt et à la diffusion de documents scientifiques de niveau recherche, publiés ou non, émanant des établissements d'enseignement et de recherche français ou étrangers, des laboratoires publics ou privés. 


\title{
PVD Coated Mill Rolls for Cold Rolling of Stainless Steel Strips - Tribological and Mechanical Laboratory Tests
}

\author{
Choumad Ould \\ MINES ParisTech \\ CEMEF, UMR CNRS 7635 \\ Sophia-Antipolis, France \\ Xavier Badiche \\ HEF R\&D, \\ Andrézieux-Bouthéon, France \\ Pierre Montmitonnet \\ MINES ParisTech \\ CEMEF, UMR CNRS 7635 \\ Sophia-Antipolis, France \\ Yves Gachon \\ HEF R\&D \\ Andrézieux-Bouthéon, France
}

\begin{abstract}
The cost of rolling is determined in particular by productivity and lifetime of rolls before regrinding. Adhesive wear of the sheet gives rise to transfer on the roll surface. Its occurrence depends on rolling conditions and is one of the determining factors of the maximal reduction for a given rolling speed. Abrasive wear of the roll is the second factor for roll lifetime. Both phenomena are strongly related to tribological and mechanical characteristics of the surface layer of rolls. Stainless steel is known for its high adhesiveness. Coatings with good tribological properties could help extend the roll service. In this paper, the potential of different PVD coatings $(\mathrm{CrN}$, TiN and TiBN) is explored. The impact of these coatings on influential phenomena during rolling is analysed thanks to well adapted tribological and mechanical laboratory tests. The results show that TiN has a good potential in cold rolling of stainless steel strips.
\end{abstract}

\section{KEYWORDS}

Strip rolling, Stainless steel, TiN PVD Coating, TiBN, CrN.

\section{INTRODUCTION}

The two major factors affecting the cost of sheet cold rolling are the productivity, determined by the pair "reduction and speed", and the lifetime of mill rolls before the degradation of their surface state necessitates their regrinding. Leaving aside shocks on the rolls, the latter is mostly decided by two wear phenomena: abrasive wear of rolls, and adhesive wear of the sheet metal which forms a transfer layer on the roll (called "roll-coating", "pick-up", i.e. local seizure).

Both wear phenomena degrade the roll surface functionality and necessitate regrinding. On the one hand, abrasive wear of the roll changes their roughness, increasing it if they are smooth, decreasing it if they are rough for better strip entrainment. This impacts both the level of friction and the surface quality of the sheet. Too low friction is a frequent cause for roll replacement in plain carbon steel rolling, whereas poor surface quality leads to downgrading the coil, in particular for stainless steels.

On the other hand, transfer impacts lubrication, positively in the case of very thin transfer layers will fill up roughness valleys and decreases $\mathrm{Ra}$ [5] [6], negatively if thick particles are transferred and build up a rougher roll surface which leads to heavy plowing of the strip surface, 
again affecting both friction and the surface quality of rolled strips [11].

The onset of transfer and adhesion is strongly related to speed and reduction and to the resulting temperature which leads to lubricant film breakdown. It is often accompanied by an abrupt increase of the coefficient of friction, thus determining the maximum possible reduction for a given roll speed [11].

Thus, everything converges to the anti-adhesive properties and abrasive wear resistance of the roll surface.

Adhesive transfer as well as hardness and abrasive wear resistance [15] of rolls are strongly related to the chemical composition of the roll surfaces. Delamare et al. [5] [6] showed that a high coverage rate of the roll surface by small, hard carbides was most favorable to form a lubricating transfer layer (as opposed to a rough, high friction one) in stainless steel rolling. Azushima and Jimbo [4] [7] came to the same conclusion for carbon steels. Certainly the low adhesion of steel to ceramics (carbides) was the reason for this improved performance.

Based on this idea, Tsubouchi et al. [16] proposed to deposit a thick layer of a powder-based Metal Matrix Composite, superalloy $+\mathrm{NbC}$ by Plasma Transferred Arc welding, for hot rolling rolls. Full ceramic rolls, or rolls with ceramic inserts, have also been proposed for cold rolling of stainless steel, e.g. [1]; such a solution however raises brittleness issues for heavy-duty rolls [2].

Another solution is to apply thin surface coatings. Coatings promoting low adhesion are well known in the rolling industry. Hard chromium electroplating has been used for a long time in the rolling of carbon steel and aluminum strips, but, to the best of our knowledge, not in cold rolling of stainless steel strips. It clearly prevents adhesive transfer, but keeps friction rather high. Moreover, it raises health issues due to the use of $\mathrm{Cr}^{\mathrm{VI}}$ baths during electroplating.

Alternative solutions exist. For many years, ceramic coatings deposited by PVD and PECVD have been used very successfully to improve wear resistance of cutting tools, decreasing friction and increasing tools life [14] [17]. These coatings are known for their very high hardness, much higher than HSS steel; they offer a wide variety of friction coefficients [10] [9]. To the authors' knowledge, these coatings have not been used in industry for mill rolls. Yet, at laboratory scale, Azushima and Jimbo studied TiN as a roll coating on low carbon steel strips cold rolling [3] [8]. They concluded that a good strip surface finish could be maintained at higher reduction, compared with uncoated rolls. TiN performed as well as hard Cr. In [12], the interest of TiN in the rolling of high carbon steel strips was investigated. The results show that adhesive wear occurs with TiN at loads similar to uncoated HSS rolls, and significantly lower than those of $\mathrm{Cr}$-plated rolls, suggesting that TiN would not allow larger reductions in rolling. Comparing [3], [8] and [12], the performance of the coating seems to be sensitive to the nature of the rolled strip.
Ould et al. [13] tested TiBN with high carbon steel and found very good performance in this application.

All this suggests that ceramic coatings could be a good solution for rolling mill rolls. Coating intended for this use must show good adhesive wear and abrasive wear resistance, good adhesion to roll steel, and good fatigue resistance because of the cyclic nature of stress during rolling. In the present study, we investigate $\mathrm{TiN}, \mathrm{CrN}$ and TiBN for stainless steel strip rolling. Anti-adhesion and fatigue resistance of the coatings is studied thanks to two well adapted tests:

- The first one is a plate-on-ring test: rings are made of roll steel, and plates are cut from strips. The rings may be PVD-coated. Conditions relevant for strip rolling are met: temperature, pressure, plastic deformation, lubrication in the mixed / boundary regime. This test has proved efficient to evaluate the anti-adhesive property of coatings. Observation of the rings after the tests allows to evaluate the level of adhesive transfer from the plate to the ring and the influence of the coating thereon.

- The twin-disk Amsler test measures the fatigue resistance of the coatings, reproducing rather well the cyclic stress met by the roll surface in strip rolling, with a significant amount of sliding and under very high pressure.

\section{MATERIALS}

Table 1. Characteristics of the materials of this study.

\begin{tabular}{|c|c|c|c|c|}
\hline Material & $\begin{array}{c}\text { Roughness } \\
\mathrm{Ra}(\mu \mathrm{m})\end{array}$ & $\begin{array}{c}\text { Scratch test } \\
\text { critical load }\end{array}$ & $\begin{array}{c}\text { Hardness } \\
\mathrm{Hv}\end{array}$ & $\begin{array}{c}\text { Coating } \\
\text { Thickness }\end{array}$ \\
\hline $\begin{array}{c}\text { TiBN- } \\
\text { coated ring }\end{array}$ & $0,10 \mu \mathrm{m}$ & $22,5 \mathrm{~N}$ & $3600 \mathrm{Hv}$ & $2,1 \mu \mathrm{m}$ \\
\hline $\begin{array}{c}\text { TiN-coated } \\
\text { ring }\end{array}$ & $0,09 \mu \mathrm{m}$ & $65 \mathrm{~N}$ & $2946 \mathrm{Hv}$ & $2,7 \mu \mathrm{m}$ \\
\hline $\begin{array}{c}\text { CrN-coated } \\
\text { ring }\end{array}$ & $0,06 \mu \mathrm{m}$ & $57 \mathrm{~N}$ & $1800 \mathrm{Hv}$ & $2,5 \mu \mathrm{m}$ \\
\hline $\begin{array}{c}\text { Uncoated } \\
\text { HSS ring }\end{array}$ & $0,07 \mu \mathrm{m}$ & - & $840 \mathrm{Hv}$ & - \\
\hline $\begin{array}{c}\text { Z100CDV5 } \\
\text { roller }\end{array}$ & $0,041 \mu \mathrm{m}$ & - & $740 \mathrm{Hv}$ & - \\
\hline $\begin{array}{c}\text { Stainless } \\
\text { steel plate }\end{array}$ & $0,17 \mu \mathrm{m}$ & - & $210 \mathrm{Hv}$ & - \\
\hline
\end{tabular}

For the ring-on-plate test, plates were cut from 1-mm thick cold rolled strips of martensitic stainless steel strips $\mathrm{X} 30 \mathrm{Cr} 13$ (AISI 1.4028 ) $0,30 \% \mathrm{C}, 13 \% \mathrm{Cr}$.

TiN, CrN and TiBN is deposited on rings made out of an HSS steel $(1.30 \% \mathrm{C}, 6 \% \mathrm{~W}, 5 \% \mathrm{Mo}, 4 \% \mathrm{Cr}, 3 \% \mathrm{~V})$ for the plate-on-ring test, on a cold work tool steel Z100CDV5 $(1 \% \mathrm{C}, 5 \% \mathrm{Cr}, 1 \% \mathrm{Mo}, 0,25 \% \mathrm{~V})$ for the Amsler test. The films were obtained by magnetron sputtering. Samples were 
coated in a TSD550 vacuum deposition unit in $\mathrm{Ar}+\mathrm{N}_{2}$ atmosphere. Deposition pressure was in the $10^{-3} \mathrm{mbar}$ range. The whole procedure was in accordance with industrial standards and included the following steps:

- Heating under a vacuum, to remove adsorbed water;

- Triode plasma etching, to remove surface oxide;

- Coating using magnetron sputtering cathode;

- Cooling under a vacuum.

During process steps with plasma, bias and power cathode were adjusted so that the temperature of the tool steel substrates never exceeded $180^{\circ} \mathrm{C}$, to avoid tempering.

The hardness, adherence and thickness of coatings have been determined on check sample (Table 1).

\section{TEST DEVICES AND PROCEDURES}

\section{The plate-on-ring test}

The plate-on-ring test measures the evolution of the coefficient of friction between an axis-symmetrical ring and a plate (Fig. 1), at varying load for a fixed rotational speed. The ring and the plate represent respectively the roll and the cold rolled stainless steel strip. The width of the active zone of the ring (the contact width) is $8 \mathrm{~mm}$. This test should highlight phenomena often observed during the rolling process, such as seizure and adhesive transfer (severe adhesive wear); it should make it possible to identify the conditions of their occurrence.

The speed is first ramped linearly; the slope and duration are chosen by the operator. For a given rotational speed, the load may be changed stepwise during the test (Fig. 2); the step duration and the load increment are also selected by the operator and are kept constant all along the test. Results are provided hereafter for a rotational speed of 600 rotations per minute (rpm); the load steps are $100 \mathrm{~N}$ every 3 minutes, from an initial $200 \mathrm{~N}$.

To avoid the concentration of wear on a very small zone and the effect of this wear on the surface of contact, the plate is given a small cyclic movement, the speed of which is negligible compared to the sliding velocity generated by the rotation of the ring. Here, the amplitude is $10 \mathrm{~mm}$.

The test can be performed dry or with lubrication. Here, the plate-on-ring device is immersed in a two-litre tank filled with steel rolling oil (Fig. 1).

The temperature can be measured using a thermocouple introduced into the oil tank through openings in the lid, at a distance from the contact. It can also be measured on the back of the plate through a hole in the support. The temperatures measured during the different tests do not exceed $80^{\circ} \mathrm{C}$. Two transducers (accuracy $\pm 0.1 \%$ ) record the normal force and torque, from which Coulomb's friction coefficient is derived.

Figure 2 gives pictures the loading procedure, and gives the correspondence between average and maximum pressures and the load applied, for the uncoated HSS rings / martensitic stainless steel plate. These values are calculated for a Hertzian contact. In reality, the plate wear tends to give a conformal contact, so that the pressure may decrease, although the displacement of the plate should somewhat limit this evolution.
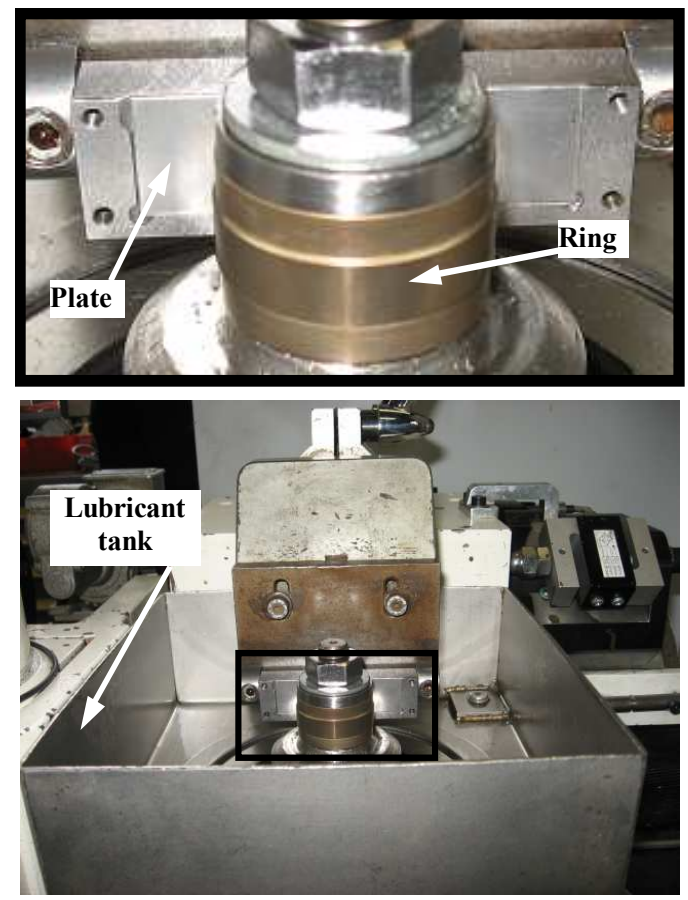

Figure 1. The plate-on-ring test device.

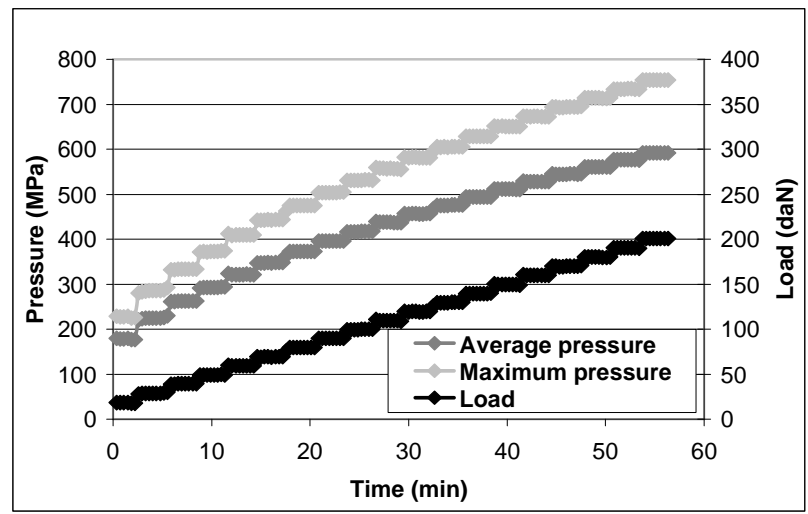

Figure 2. Pressure - load correspondence; uncoated HSS ring against stainless steel plate (Hertzian contact).

\section{The Amsler Test}

A twin-disk Amsler machine is used to evaluate the fatigue resistance of the coatings under cyclic contact 
loading. The two identical rollers are $50 \mathrm{~mm}$ in diameter and have rounded contact surfaces (Fig. 3) so as to obtain a point contact. The base material is a cold work tool steel Z100CDV5 (1\%C，5\% Cr, 1\% Mo, $0.25 \% \mathrm{~V})$, either uncoated, or TiBN, CrN or TiN coated (Table 1).

The loading frequency is determined by the rotational speeds. The two rotational velocities are different, to work under rolling / sliding conditions. Here, based on slide / roll ratio occurring in strip rolling, roller speeds of 380 and 350 $\mathrm{rpm}$ have been selected, giving a sliding speed of $0,08 \mathrm{~m} / \mathrm{s}$ ( $\mathrm{SRR}=8 \%$ ). The loading frequency is therefore $\sim 6 \mathrm{~Hz}$, and the load on a material element of the roller lasts about 0.98 $\mathrm{ms}$ at each rotation. Two transducers (accuracy $\pm 0.1 \%$ ) record the normal force and torque, from which Coulomb's friction coefficient is derived. Two types of tests have been carried out on this machine:

- A friction test during which the imposed load increases stepwise from $237.5 \mathrm{~N}$ to $1663 \mathrm{~N}$. The selected increment is $237.5 \mathrm{~N}$, the load step length is 30 minutes. Apart from the evolution of the coefficient of friction with load, the goal is to determine the failure load of the coating, manifested by a friction peak.

- An endurance test for a fairly long period, about fifty hours. The load selected here is the last one before coating failure in the friction test; it is applied progressively in the first hour (load increment is 237.5 $\mathrm{N}$ and load step length is 10 minutes), then kept constant. All tests are lubricated with neat rolling oil.
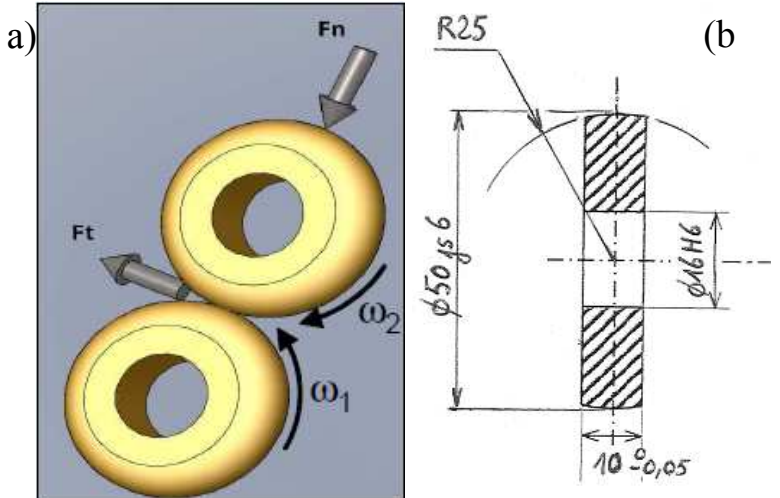

Figure 3. A general sketch of the Amsler test. (a) principle, (b) geometry of rollers.

\section{RESULTS OF THE PLATE-ON-RING TEST}

Several tests have been carried out to evaluate the coefficient of friction and adhesive transfer occurrence with TiN, CrN and TiBN coatings, and to compare it with uncoated ring under the same test conditions.

\section{Friction evolution and correlation with adhesion}

Figure 4 presents the results of two tests made under the same conditions with uncoated rings $(600 \mathrm{Rpm}$, same load increase protocol). This good reproducibility has been found systematically.

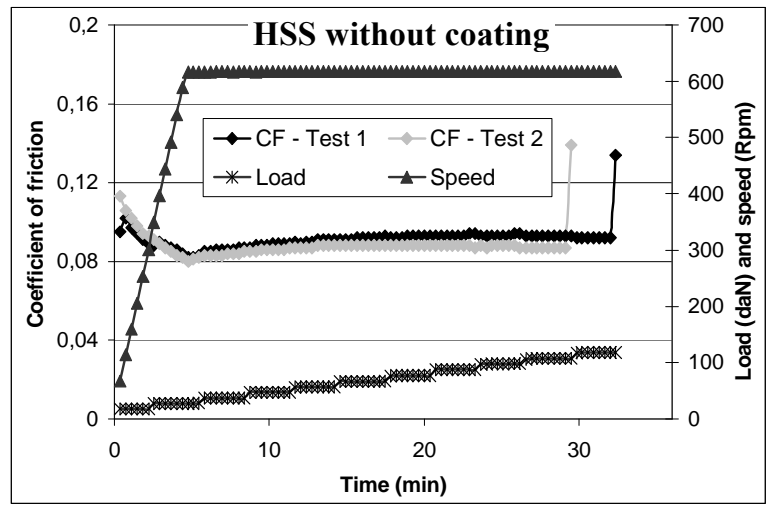

Figure 4. Friction evolution during the plate-on-ring test. Uncoated HSS rings / stainless steel plates / neat rolling oil.
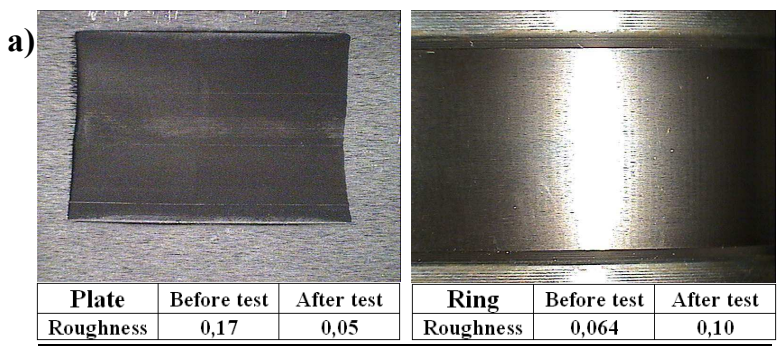

b)

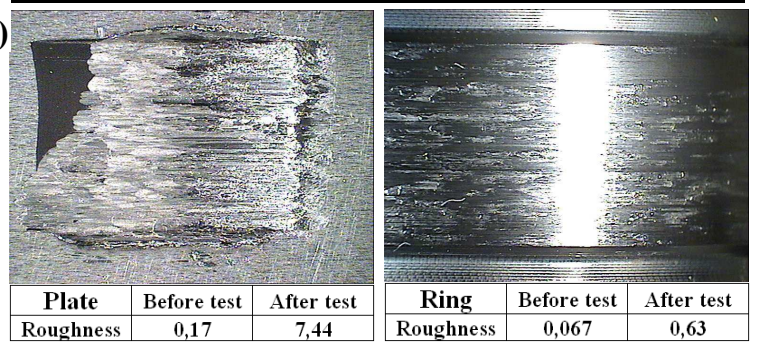

Figure 5. Influence of adhesive wear on the surface state of plate (left) and uncoated HSS ring (right): before adhesive wear (a), after adhesive wear (b). Roughness is quoted as $\mathrm{Ra}(\mu \mathrm{m})$. Roughness measurement conditions: sampling length $\mathrm{L}=4 \mathrm{~mm}$, cut-off $\lambda \mathrm{c}=0.8 \mathrm{~mm}$.

The evolution of the coefficient of friction shows three distinct stages:

- Stage 1: in the speed ramp, friction decreases gradually.

This is attributed to growing hydrodynamic effects;

- Stage 2: friction is relatively stable; 
- Stage 3: a large and sudden rise in friction caused [12] by the onset of severe adhesive wear. It is not systematic. In the case of uncoated rings, it begins at 1200 N (Fig. 3).

When stage 3 occurs, the test is stopped to avoid excessive degradation of the surfaces.

Figure 5 proves that adhesion is the cause of stage 3 . Surfaces of rings and plates have been studied before and after the onset of stage 3 :

- In stage 2, the uncoated ring surface remains smooth and bright, although its roughness seems to increase slightly; due to wear, the plate roughness goes down to $\mathrm{Ra} \approx 0,05 \mu \mathrm{m}$;

- In stage 3, both surfaces are degraded: a lot of large stainless steel particles are visible on the ring surface, resulting in a rapid increase of ring roughness. This adhesive wear is accompanied by heavy ploughing of the plate surface, which is also considerably roughened.

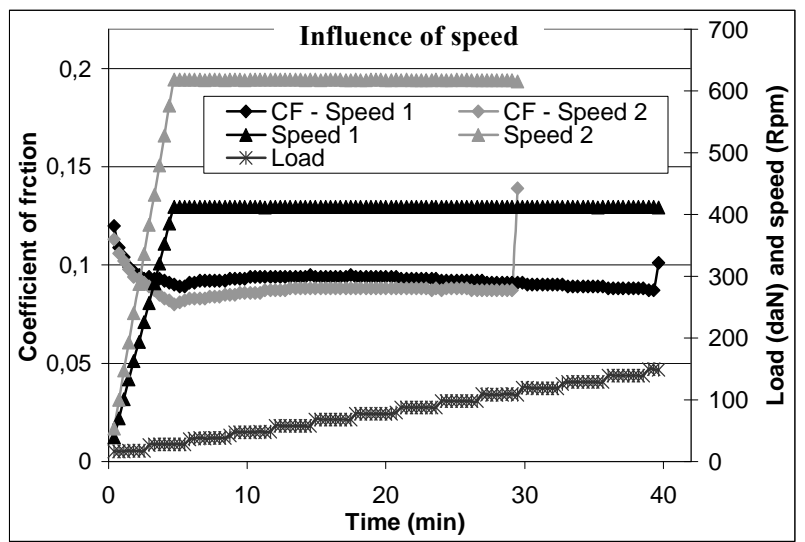

Figure 6. Plate-on-ring tests (uncoated HSS ring): influence of speed on the critical load for adhesive wear.

Seizure is due to the destruction of oxide layers and welding of the naked metals. It is correlated with the amount of energy input in the system, and the contact temperature. The (speed, load) couple is determinant in this respect. Therefore, the influence of speed on load-friction curves has been investigated. Two tests have been carried out at different speeds (400 and $600 \mathrm{rpm}$, Fig. 6):

- whatever the speed, the friction coefficient evolution shows the same three stages as previously;

- higher speed leads to slightly lower friction in stage 2, suggesting a small hydrodynamic effect; yet, the difference is of the order of measurement uncertainty.

- the higher the speed, the lower the load at which severe adhesive wear (stage 3 ) occurs, and the more friction increases in stage 3, as already observed in Ould et al., $2011[12]$

\section{Comparison of the coatings}

TiBN showed the best tribological properties for high carbon steel plates [13]. Figure 7 reports results of tests on stainless steel, carried out under the same conditions as figure 4 . The three stages are found, i.e. with TiBN coating, adhesive wear occurs at a load of $900 \mathrm{~N}$; it was $1200 \mathrm{~N}$ for the uncoated rings. In the first and second stages (i.e. up to 20 minutes), the coefficient of friction of TiBN-coated rings is significantly more unsteady than with uncoated HSS steel rings, suggesting minor adhesion takes place and is eliminated repeatedly.

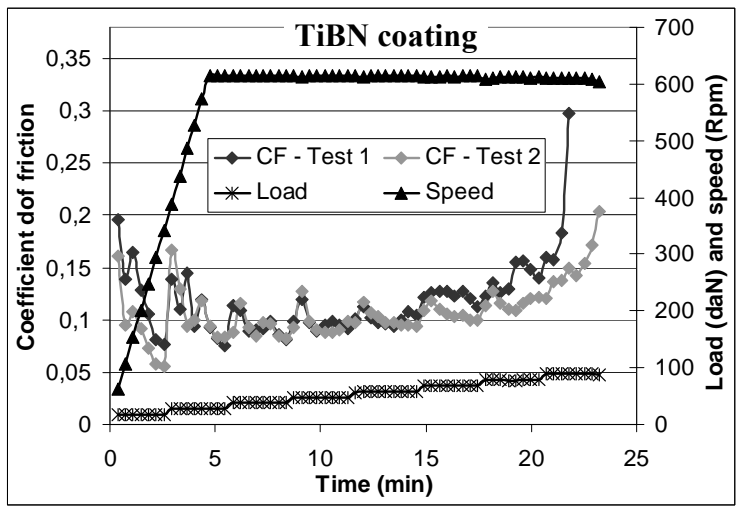

Figure 7. Plate-on-ring tests results with TiBN-coated HSS rings / stainless steel plates / neat rolling oil.

Unlike TiBN and uncoated HSS, TiN and CrN (Fig. 8) show no stage 3 with stainless steel plates, suggesting no adhesive wear is taking place until the end of the test at $2000 \mathrm{~N}$.

The comparison of load - friction curves with uncoated rings, TiBN-coated rings and TiN-coated rings (Fig. 9) leads to the following observations:

- TiBN-coated rings are characterized by instability and adhesive wear occurring at a load as low as $900 \mathrm{~N}$, lower than with uncoated rings $(1200 \mathrm{~N})$;

- Friction is stable with TiN, although tiny peaks in stage 2 suggest again reversible, minor adhesion. Friction is higher than with uncoated rings below a $1000 \mathrm{~N}$ load. Stage 3 does not occur until $2000 \mathrm{~N}$.

$\mathrm{CrN}$ and $\mathrm{TiN}$ are compared in figure 9b. Friction coefficients are very similar at all loads. In terms of adhesive wear as well, the performance of the two coatings is similar. The coefficient of friction in stage 2 is more stable with $\mathrm{CrN}$. 


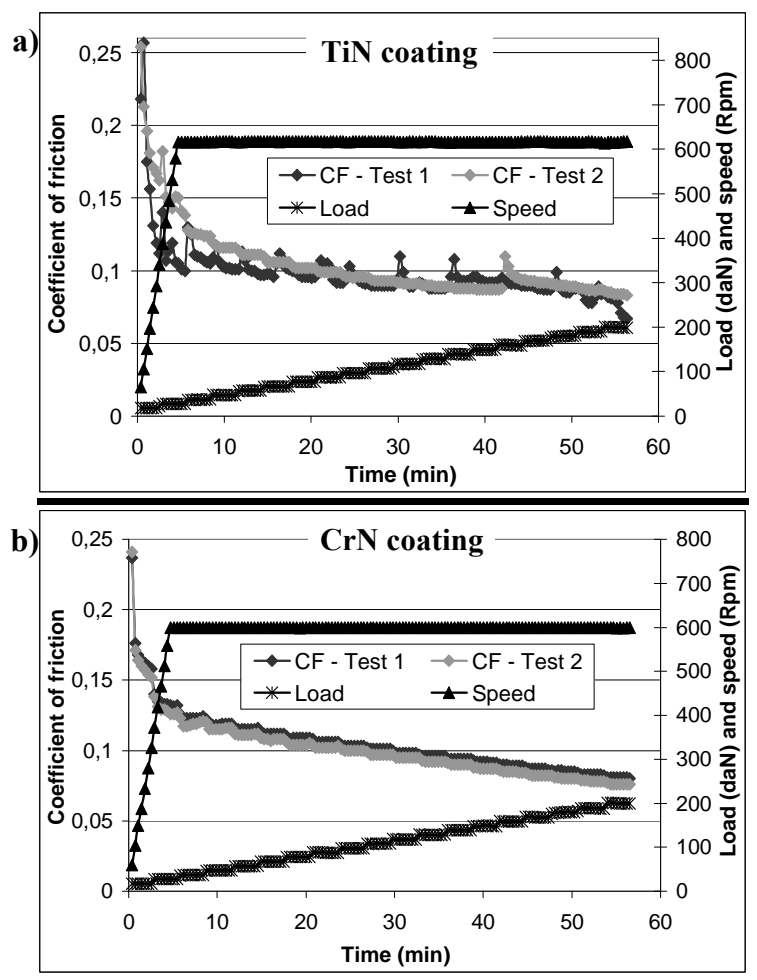

Figure 8. Plate-on-ring tests results with coated HSS rings / stainless steel plates / neat rolling oil (a) TiN, (b) $\mathrm{CrN}$.
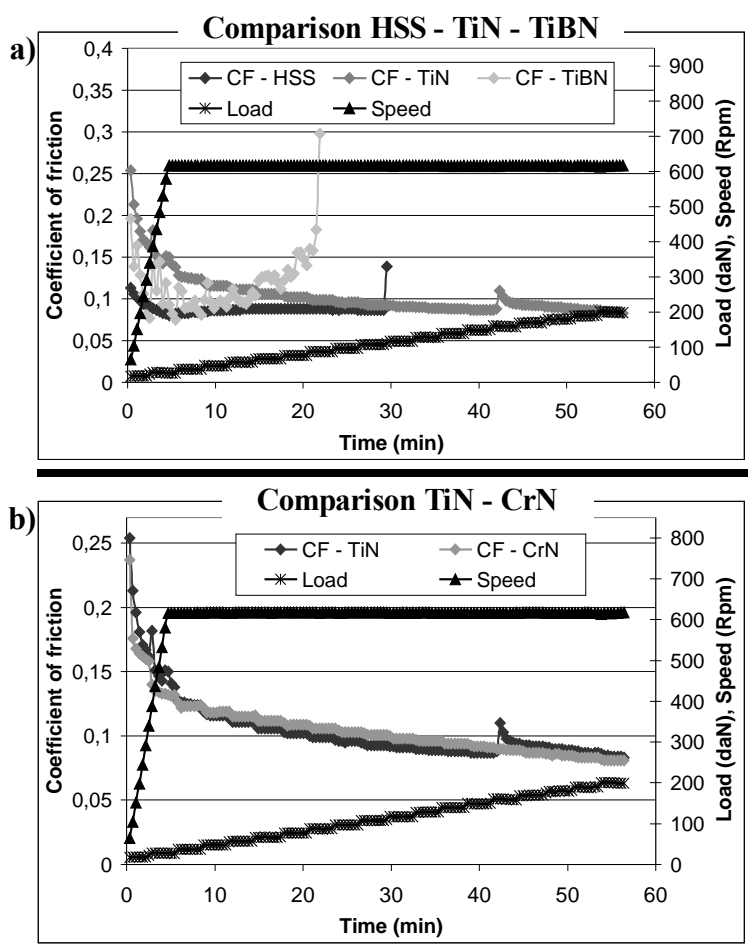

Figure 9. Comparison of uncoated, TiBN-coated and TiNcoated rings (a); of $\mathrm{CrN}$-coated and TiN-coated rings (b).

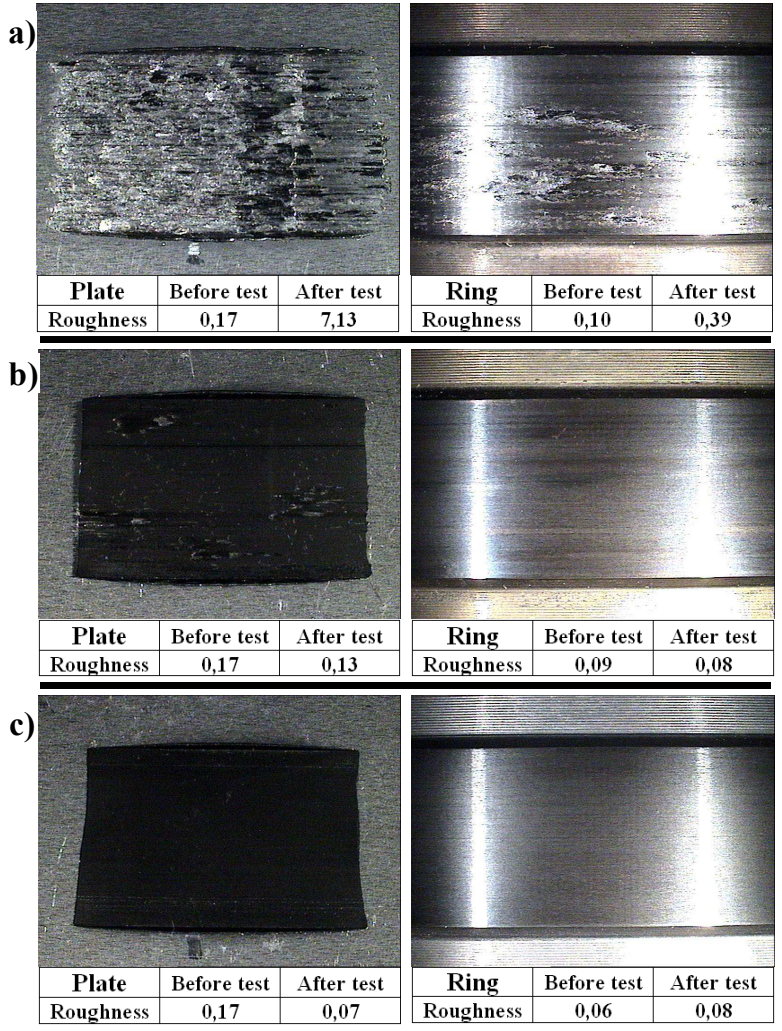

Figure 10. Surfaces state of plates (left) and rings (right) after tests: TiBN-coated ring (a), TiN-coated ring (b) and $\mathrm{CrN}$-coated ring (c). Roughness is quoted as $\mathrm{Ra}(\mu \mathrm{m})$. Roughness measurement conditions: sampling length $\mathrm{L}=4$ $\mathrm{mm}$, cut-off $\lambda \mathrm{c}=0.8 \mathrm{~mm}$.

Figure 10 investigates the surface states for adhesion. With TiBN (Fig. 10a), severe adhesive wear is observed with almost the same intensity and the same effects, but at lower load than with uncoated rings.

The same analysis has been done at the end of tests with TiN-coated and CrN-coated rings (Fig. $10 \mathrm{~b}$ and 10c). It shows that:

- The bright and smooth aspect of the TiN- and CrNcoated rings shows that no massive adhesion has taken place, although tests were run until the maximum load, $2 \mathrm{kN}$;

- the plate roughness decreases with $\mathrm{CrN}$-coated rings, from $\mathrm{Ra}=0,17 \mu \mathrm{m}$ to $0,07 \mu \mathrm{m}$, and with TiN-coated rings, from $0,17 \mu \mathrm{m}$ to $0,13 \mu \mathrm{m}$. : smoothing is slightly more complete with $\mathrm{CrN}$ than with $\mathrm{TiN}$;

- The roughness on TiN-coated and $\mathrm{CrN}$-coated rings at the end of tests is practically identical to the initial roughness.

These results show that, in terms of anti-adhesive properties, the level of performance of $\mathrm{TiN}$ and $\mathrm{CrN}$ is very high and generally quite similar. 


\section{ANALYSIS OF THE TRANSFER LAYER}

The $\mathrm{CrN}$ and TiN coatings have showed good antiseizure performance. This is an important property which determines the maximum reduction in cold rolling, it therefore deserves complete investigation. Although adhesive wear could not be observed by eye after the test, nor by its effects on friction during the tests, it is not impossible that minor adhesive transfer took place during the test, as shown by some instability of the load-friction curve of TiN e.g. In the long run, a difference between the two coatings may show and determine which one is the best candidate for tests on the rolling mill. This is why the presence of transfer particles has been investigated in more details. In case elements from the plate $(\mathrm{Fe}, \mathrm{Cr})$ are detected on the ring, their concentration will allow comparing quantitatively the anti-adhesive tendencies of TiN versus $\mathrm{CrN}$. For this analysis, a Scanning Electron Microscope (SEM) and energy dispersive X-ray (EDX) (Hitachi S-3400 $\mathrm{N})$ was used at $15 \mathrm{kV}$. Analyses were performed on a $\mathrm{CrN}$ coated and a TiN-coated ring after plate-on-ring tests. On each of the rings two zones were analyzed:

- The 8-mm wide zone, which was in contact with the stainless plate during the test;

- The no-contact zone.

The surface of analyzed area is $250 \mu \mathrm{m} \times 250 \mu \mathrm{m}$.

Table 2. Chemical composition in contact zone and no-contact zone of $\mathrm{CrN}$-coated ring after test.

\begin{tabular}{|c|c|c|}
\cline { 2 - 3 } \multicolumn{1}{c|}{} & Out of contact zone & Contact zone \\
\hline Element & Atom $\%$ & Atom \% \\
\hline$C K$ & 9.21 & 8.68 \\
\hline$N K$ & 32.38 & 27.40 \\
\hline$O K$ & 3.86 & 13.27 \\
\hline Al $K$ & 0.19 & 0.25 \\
\hline Si $K$ & 0.25 & 0.22 \\
\hline Cr $K$ & 53.38 & 46.99 \\
\hline $\boldsymbol{F e} \boldsymbol{K}$ & $\mathbf{0 . 6 0}$ & $\mathbf{2 . 9 9}$ \\
\hline Ni $K$ & 0.12 & 0.21 \\
\hline Total & 100.00 & 100.00 \\
\hline
\end{tabular}

Carbon and oxygen (Tables 2 and 3) come mainly from the oil contamination film, and the oxide layers. What is characteristic of adhesive transfer is the presence of $\mathrm{Fe}$ in both cases, and $\mathrm{Cr}$ on $\mathrm{TiN}$. in the no-contact zone, $\mathrm{Fe}$ is very low $(\sim 0,6 \%)$, meaning that the maximum depth of emission slightly exceeds the thickness of the layer, so that some iron from the steel substrate is detected. By comparison, the presence of iron in the contact zone, $\sim 3 \%$, is judged significant, but represents a relatively low level of transfer in both cases.
Table 3. Chemical composition in contact zone and nocontact zone of TiN-coated ring after test.

\begin{tabular}{|c|c|c|}
\cline { 2 - 3 } \multicolumn{1}{c|}{} & Out of contact zone & Contact zone \\
\hline Element & Atom $\%$ & Atom $\%$ \\
\hline$C K$ & 3.94 & 3.91 \\
\hline$N K$ & 52.04 & 33.63 \\
\hline$O K$ & 0.00 & 20.98 \\
\hline$T i K$ & 43.29 & 37.96 \\
\hline Cr $\boldsymbol{K}$ & $\mathbf{0 . 0 1}$ & $\mathbf{0 . 3 9}$ \\
\hline $\boldsymbol{F e} \boldsymbol{K}$ & $\mathbf{0 . 6 5}$ & $\mathbf{3 . 0 8}$ \\
\hline Ni $K$ & 0.07 & 0.04 \\
\hline Total & 100.00 & 100.00 \\
\hline
\end{tabular}

Note also that, in the case of the TiN-coated ring, the $\mathrm{Cr}$ / Fe ratio in the contact zone is compatible with the stainless steel composition ( $13 \% \mathrm{Cr} / 87 \% \mathrm{Fe})$, confirming that $\sim 2.5 \%$ Fe comes from a transfer film.

These analyses prove that even if no degradation of friction is observed, transfer is present, similar for TiN and $\mathrm{CrN}$, covering a small fraction of the surface with tiny particles. On the contrary, TiBN and the naked HSS are coated with stainless steel on a major fraction of their surface, with big particles, increasing friction very significantly and degrading plate surface. This duality, an example of the difference between mild and severe wear, has already been pointed out: the distinction between the mild wear of $\mathrm{CrN}$ or $\mathrm{TiN}$, and the severe wear of TiBN or HSS, is very similar to the transition observed in cold rolling of stainless steel when increasing the reduction [11].

\section{STUDY OF COATING FATIGUE RESISTANCE}

\section{Amsler friction test}

In the Amsler friction tests (Fig. 11), the evolution of $\mu$ with load is rather similar to what has been observed in the ring-on-plate tests. At the beginning of the test, $\mu_{\mathrm{TiN}}>\mu_{\text {steel }}$ $>\mu_{\mathrm{TiBN}}$. For TiBN rings, $\mu$ increases with the load before stabilizing. On the contrary, for both TiN-coated and uncoated rollers, the coefficient of friction decreases, then stabilizes. The final, stabilized coefficients are almost identical for all cases $(\mu \approx 0,09)$. CrN is different. The friction coefficient decreases and stabilizes at a higher value $\left(\mu_{\mathrm{CrN}} \approx 0,115\right)$. The ranking of the friction coefficients does not correlate with e.g. the initial coating roughness (table 1).

All coatings resist all applied loads, neither chipping nor seizure was observed at the end of the tests. Therefore, endurance tests have been carried out at the maximum load of $1663 \mathrm{~N}$, giving a Hertz average pressure of about 2.2 $\mathrm{GPa}$, for a total duration of fifty hours (1.08 $10^{6}$ cycles $)$. 


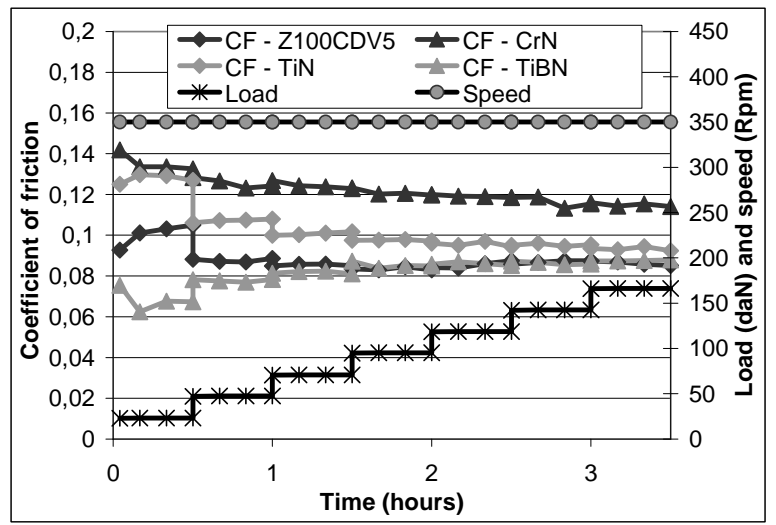

Figure 11. Amsler friction test (neat oil lubrication): evolution of the coefficient of friction with increasing load.

\section{Amsler endurance tests: frictional behaviour}

In the endurance tests, once the full load is reached, friction stabilizes again at $\mu=0,09$ for all three materials pictured in figure 12: uncoated tool steel, TiBN and TiN.

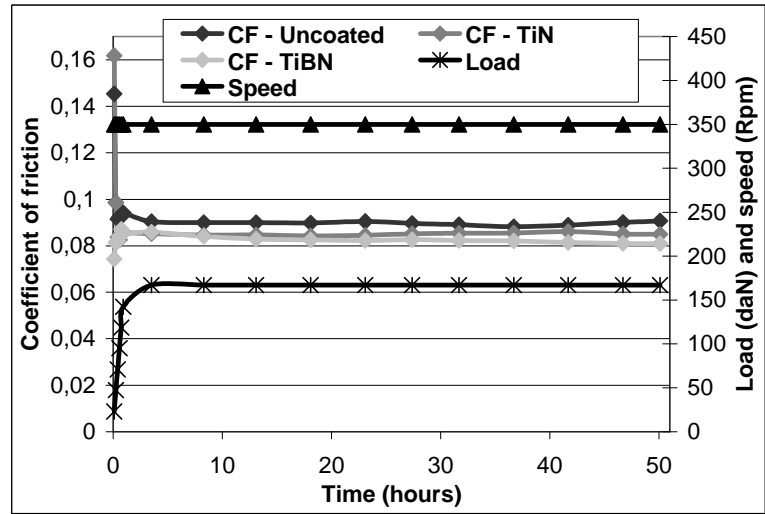

Figure 12. Amsler endurance tests (50 hours, pressure 2.2 $\mathrm{GPa}$, neat oil lubrication) for uncoated, TiN-coated and TiBN-coated rollers.

For the $\mathrm{CrN}$ coated rollers, after about twenty hours of test, the coefficient of friction increases abruptly (Fig. 13). The test was carried out twice with the same result at the same time, pointing to a reproducible, therefore significant phenomenon.

\section{Amsler endurance tests: surface integrity}

The micrographic analyses of the uncoated rollers after the endurance tests show intergranular fatigue cracks under the contact zone (Fig. 14). No crack is detected outside the contact track. At a load of $2.2 \mathrm{GPa}$, the Hertz point is approximately $0.25 \mathrm{~mm}$ below the contact surface, much deeper than the cracks observed here $(9$ to $14 \mu \mathrm{m})$. This suggests that these are fatigue cracks induced by the much more superficial shear stresses due to friction.

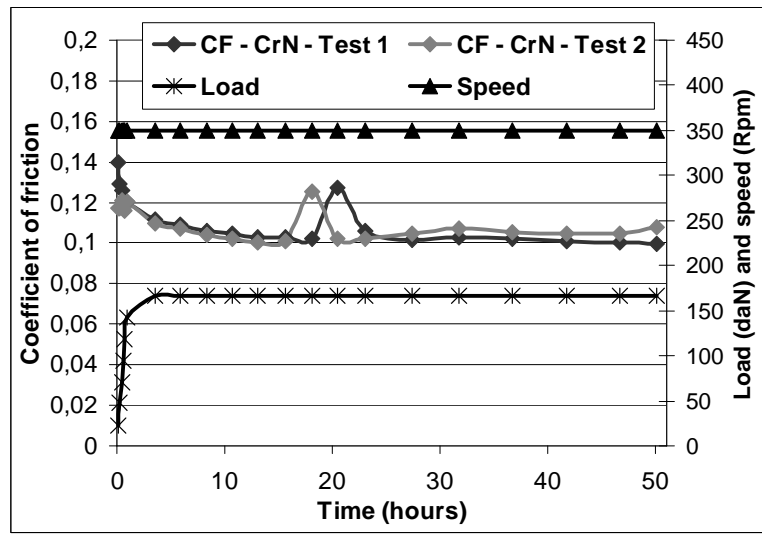

Figure 13. Amsler endurance tests (50 hours, pressure 2.2 $\mathrm{GPa}$, neat oil lubrication) for $\mathrm{CrN}$-coated rollers.

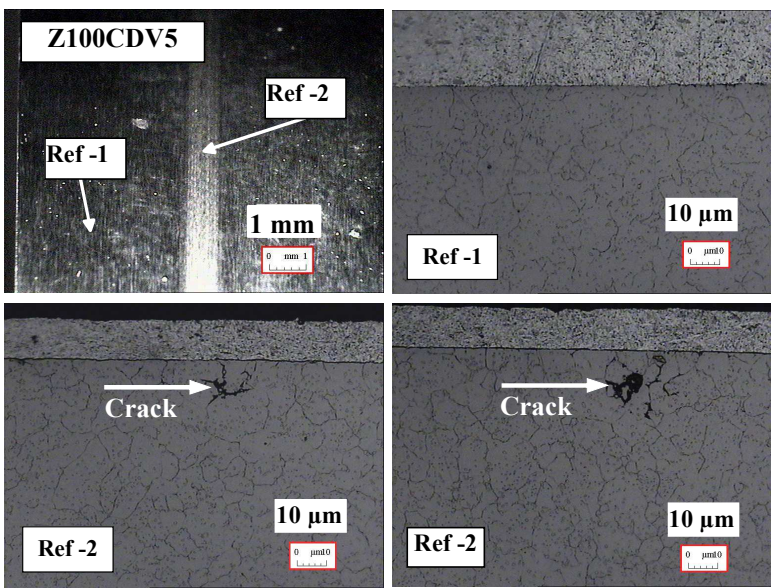

Figure 14. Cross sectional optical microscopy of uncoated Z100CDV5 rollers after endurance test. Top Right: outside contact track. Bottom: inside contact track.

For TiBN and TiN, the residual thickness of the coatings measured after fifty hours tests shows a reduction by $\approx 0,3$ $\mu \mathrm{m}$ due to slow abrasive wear. However, coatings remain on the rollers until the end of the test (Fig. 15 and 16): no cracks have been observed, either in the coating or beneath it. Endurance tests of a longer duration, 125 hours $(2,7$ million cycles), were carried out. These two coatings have withstood this longer test.

The compressive residual stresses generated by the PVD process has a maximum at the interface [9]; moreover, the coefficients of thermal expansion are close to the substrate 
steel $\left(9.410^{-6}\right.$ for TiN and TiBN versus $11.510^{-6}$ for steel). These are probably the reasons why these coatings resist the severe conditions of the tests. The improvement of the substrate fatigue resistance is certainly due to the coatings reducing the stress transmitted to the substrate. However, the mechanisms by which these coatings improve fatigue resistance deserve further study.

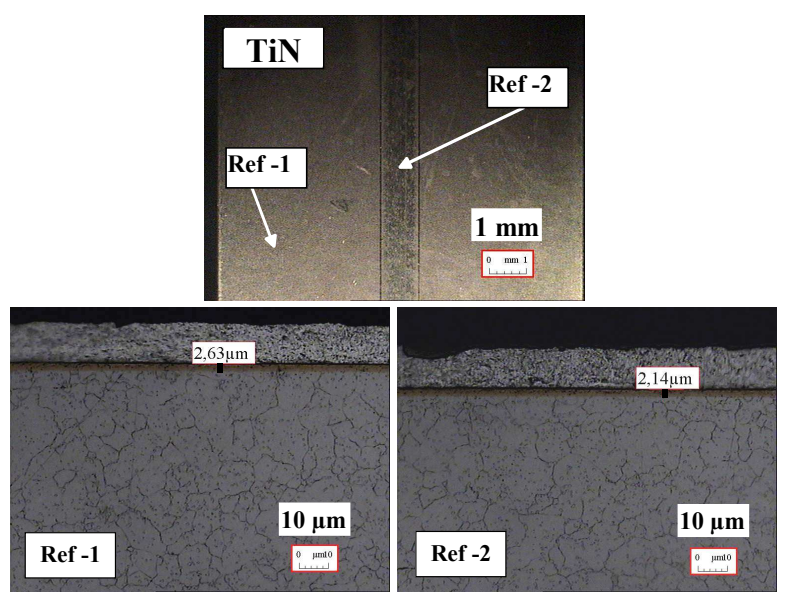

Figure 15. Optical microscopy of cross sections of the TiNcoated Z100CDV5 rollers after endurance test. Initial coating thickness: $2.7 \mu \mathrm{m}$. Left: outside contact track. Right: inside contact track.

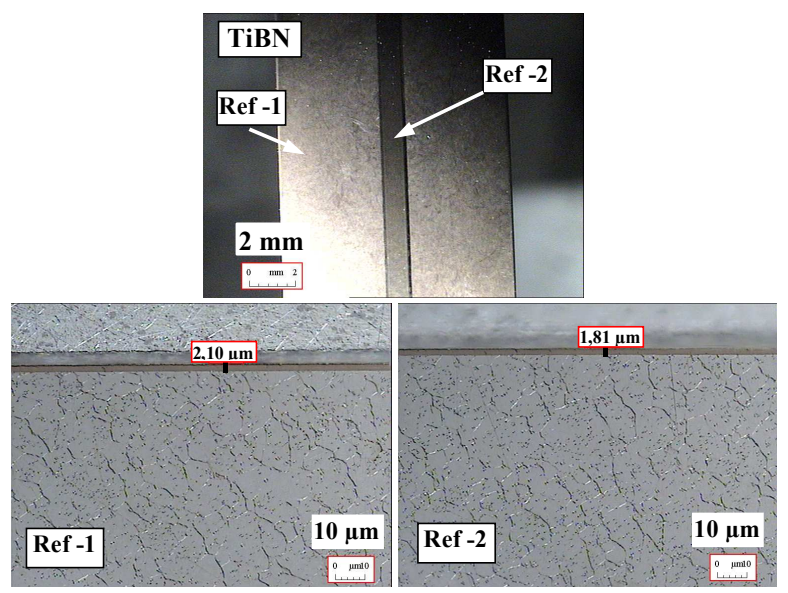

Figure 16. Optical microscopy of cross sections of TiBNcoated Z100CDV5 rollers after endurance test. Initial coating thickness: $2.1 \mu \mathrm{m}$. Left: outside contact track. Right: inside contact track.

The CrN coating was removed from the contact zone (Fig. 17). This explains the friction growth after 20 hours (Fig. 13): this is the moment where the coating flaked as a result of fatigue, releasing in the lubricant hard particles with high abrasive power. The wide gap in the coefficient of thermal expansion between $\mathrm{CrN}$ and steel substrate $\left(2.310^{-6}\right.$ for $\mathrm{CrN}$ versus $11.510^{-6}$ for steel) results in very high deposition stress [10]. Although compressive, they cause this low fatigue resistance when contact stresses are superimposed.

The high tribological performance of $\mathrm{CrN}$ (good antiadhesive wear and anti-transfer properties) is unfortunately impaired by a low fatigue resistance. It is suggested that $\mathrm{Cr}_{\mathrm{x}} \mathrm{N}_{\mathrm{y}}$ (a mixture of $\mathrm{Cr}, \mathrm{CrN}$ and $\mathrm{Cr}_{2} \mathrm{~N}$ with varying percentage depending on deposition conditions) could have a high potential in this application. Indeed, $\mathrm{Cr}_{\mathrm{x}} \mathrm{N}_{\mathrm{y}}$, by its chemical composition similar to $\mathrm{CrN}$, should have similar tribological properties; its coefficient of thermal expansion is much closer to steel, providing a better resistance to thermo-mechanical fatigue. The advantage of this coating in this application will be the subject of a future study.

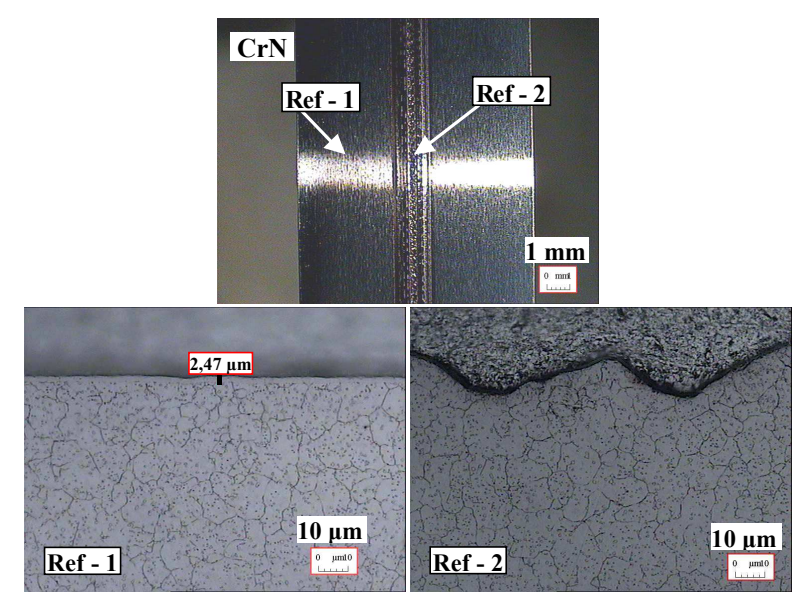

Figure 17. Optical microscopy of cross sections of the CrN-coated Z100CDV5 rollers after endurance test. Initial coating thickness: $2.5 \mu \mathrm{m}$. Left: outside contact track. Right: inside contact track.

\section{CONCLUSION}

The potential of PVD coatings, TiN, $\mathrm{CrN}$ and TiBN, as coatings for mill rolls in stainless steel strip cold rolling of has been analyzed, by evaluating the tribological properties and contact fatigue resistance; both types of properties are essential for productivity.

These coatings were compared to uncoated steel currently used in this industry. In terms of resistance to adhesive wear, TiBN is less efficient than uncoated steel whereas TiN and $\mathrm{CrN}$ have excellent anti-adhesion capacities. This suggests possible substantial improvement in the maximum possible reduction.

In terms of fatigue resistance, $\mathrm{TiN}$ and $\mathrm{TiBN}$ show promising performance, resisting 2.7 million cycles at a 
Hertz pressure of $2.2 \mathrm{GPa}$. It even seems that they can protect the substrate against superficial fatigue. On the contrary, CrN flakes off after 0.3 million cycles only.

Altogether, TiN, which resists both transfer and fatigue, possesses both properties judged necessary for a good PVD coating for rolls, enabling substantially higher productivity than uncoated steel rolls for cold rolling of stainless steel strip. Tests of coated rolls in a rolling mill are planned in the near future.

With the same tests of the same properties, [12] [13] concluded that TiBN was the best potential coating for high-C steel cold rolling, and TiN performed poorly. This shows the importance of matching the coating of the rolls with the nature of the strip metal.

Based on the present work, tests on small size mills are being carried out. Furthermore, a large size reactor is being commissioned, making it possible to coat large size rolls (up to $2.8 \mathrm{~m}$ in length and more than $1 \mathrm{~m}$ in diameter).

\section{ACKNOWLEDGEMENT}

The authors are grateful to the French Ministry of Industry, to the Rhone-Alpes Region, to the Conseil Général of the Loire département, and to Saint-Etienne Métropole, for funding the DURACYL Project. They thank the partners HEF R\&D, Constellium CRV, and Paturle Aciers for technical discussions and authorization to present this work.

\section{REFERENCES}

[1] Andersson P, Wild M, Leven J, Hemming B (2006) Transfer of surface texture from silicon nitride rolls to stainless steel wire in cold rolling. J. Mat. Proc. Tech. 173, 3, 394-400.

[2] Andersson P, Leven J, Hemming B (2009) Hot rolling tests with steel bars and silicon nitride rolls. J. Mat. Proc. Tech. 209, 884-893.

[3] Azushima A, Morita Y (1992) Lubrication characteristics of surface treated rolls. ISIJ Int 32, 1232-1237.

[4] Azushima A, Jimbo Y (1995) Effect of carbide properties on lubrication characteristics of roll in cold sheet rolling, Tetsu to Hagane 81, 12, $42-47$ (in Japanese).

[5] Delamare F, de Vathaire M, Kubié J (1982a) An evaluation of the PSCT. II - experimental study of the friction test: role of the transfer layer in boundary lubrication, J. Lub. Technol. (Trans. ASME), 104, 545-551.

[6] Delamare F, Kubié J (1982b) An evaluation of the PSCT. III - experimental study of the friction test: the role of the metallurgical parameters of die and sheet, J. Lub. Technol. (Trans. ASME), 104, 538544.
[7] Jimbo Y, Azushima A (2001a) Effect of carbide properties of roll materials on lubricity in cold sheet rolling of low-carbon steel. Int. J. Mach. Tools Manuf. 41, 347-360.

[8] Jimbo Y, Azushima A (2001b). Lubrication characteristics of physical vapor deposition TiNcoated roll for high productivity in cold rolling of low-carbon steel sheet. Wear 249, 215-221.

[9] Mandibide C (2003) Caractérisation des revêtements PVD à base de nitrures de métaux de transition pour application mécanique (Characterization of transition metals nitride based coatings for mechanical applications), Ph.D. Dissertation, INSA Lyon (in French).

[10] Montes de Oca Valero JA (2002) Elaboration du carbure et du nitrure de titane par des procédés chimiques et physiques en phase vapeur : caractérisation de la microstructure (Elaboration of TC and TiN by CVD and PVD processes: microstructural characterization), Ph.D. Dissertation, University Bordeaux I (in French).

[11] Montmitonnet P, Delamare F, Rizoulières B (2000) Transfer layer and friction in cold metal strip rolling processes, Wear 245, p.125-135.

[12] Ould C, Gachon Y, Montmitonnet P, Badiche X (2011a) Tribological Testing of Anti-Adhesive coatings for Cold Rolling Mill Rolls - Application to TiN-Coated Rolls. In: Proc. ESAFORM Conf. (April 27-29, 2011, Belfast, Northern Ireland) 17471752.

[13] Ould C, Badiche X, Montmitonnet P, Gachon Y (2011b) Feasibility of TiBN PVD Coating for Mill Rolls - Laboratory Testing of Anti-adhesive and Fatigue Resistance Properties. In: Proc. ICTP Conf. (September 25-30, 2011, Aachen, Germany), 9-14.

[14] Prengel HG, Jindal PC, Wendt KH, Santhanam AT, Hedge PL, Penich RM (2001) A new class of high performance PVD coatings on cemented carbide cutting tools. Surf. Coat. Techn. 139, 25-34.

[15] Rodenburg C, Rainforth WM (2007) A quantitative analysis of the influence of carbides size distributions on wear behavior in high-speed steel in dry rolling / sliding contact. Acta Mat. 55, 24432454.

[16] Tsubouchi K, Akiyama M, Tsumura M, Amano S (1999) Development of a wear-resistant surface layer for a tool to be used for high temperature stainless steel rolling. Proc. Instn. Mech. Engrs J, 213, 473-480.

[17] Zhang ZG (2008) Elaboration de dépôts nanocomposés par pulvérisation cathodique magnétron pour la substitution du chrome électrolytique (Elaboration of nanostructured coatings by Magnetron Cathodic Sputtering as substitutes of electrolytic Cr), Ph.D. Dissertation, UTBM (in French). 